\title{
POINTWISE STRONG APPROXIMATION OF ALMOST PERIODIC FUNCTIONS IN $S^{1}$
}

\author{
WŁODZIMIERZ ŁENSKI AND BOGDAN SZAL
}

Abstract. We consider the Fourier series of $S^{1}$ almost periodic functions and construct the matrix means of partial sums of such series by the class $G M\left({ }_{2} \beta\right)$. In two approximation theorems using these means we give the estimates of pointwise strong deviation of such means from the functions in terms of moduli of continuity defined by the Gabisoniya points, and the best approximation of functions by entire functions.

Mathematics subject classification (2010): 42A247.

Keywords and phrases: Almost periodic functions, rate of strong approximation, summability of Fourier series.

\section{REFERENCES}

[1] A. D. Bailey, Almost Everywhere Convergence of Dyadic Partial Sums of Fourier Series for Almost Periodic Functions, Master of Philosophy, A thesis submitted to School of Mathematics of The University of Birmingham for the degree of Master of Philosophy, September 2008.

[2] A. S. Besicovitch, Almost periodic functions, Cambridge, 1932.

[3] O. D. GabisoniYa, Points of strong summability of Fourier series, (Translated from Matematicheskie Zametki, Vol. 14, No. 5, pp. 615-626) Math. Notes 14 (1973), 913-918 (1974).

[4] R. KRANZ, W. ŁensKi AND B. SZAL, Pointwise strong approximation of almost periodic functions, (http://arxiv.org/pdf/1204.2953.pdf), submitted.

[5] R. J. LE AND S. P. ZHOU, A new condition for the uniform convergence of certain trigonometric series, Acta Math. Hung., 108 (1-2) (2005), 161-169.

[6] L. LEINDLER, On the uniform convergence and boundedness of a certain class of sine series, Analysis Math., 27 (2001), 279-285.

[7] L. LeIndLER, A new extension of monotone sequence and its application, J. Inequal. Pure and Appl. Math., 7 (1) (2006), Art. 39, 7 pp.

[8] W. ŁENS KI, Pointwise strong and very strong approximation of Fourier series, Acta Math. Hung., 115 (3), 207, p. 215-233.

[9] W. ŁENSKI AND B. SZAL, Strong approximation of almost periodic functions, Math. Inequal. Appl. 17, 4 (2014). 1353-1364.

[10] B. L. LeVITAN, Almost periodic functions, Gos. Izdat. Tekh-Teoret. Liter., Moscov 1953 (in Russian),

[11] J. MARCinkiewicz, Sur la sommabilite forte de series de Fourier, J. London Math. Soc. 14 (1939), pp. $162-168$.

[12] P. PYCH-TABERSKA, Approximation properties of the partial sums of Fourier series of almost periodic functions, Studia Math. XCVI (1990), 91-103.

[13] S. TIKHONOV, Trigonometric series with general monotone coefficients, J. Math. Anal. Appl., 326 (1) (2007), 721-735.

[14] S. Tikhonov, On uniform convergence of trigonometric series, Mat. Zametki, 81 (2) (2007), 304 310, translation in Math. Notes, 81 (2) (2007), 268-274.

[15] S. Tikhonov, Best approximation and moduli of smoothness: Computation and equivalence theorems, J. Approx. Theory, 153 (2008), 19-39. 